\title{
Thoracic endograft in traumatic aortic injury - an other job for cardiologist in University Hospital Center Zagreb
}

\author{
Maja Strozzi* \\ University Hospital Center Zagreb, Zagreb, Croatia
}

Thoracic endovascular aortic repair (TEVAR) initially developed for the treatment of degenerative aneurysms of the descending thoracic aorta, has been applied to the entire spectrum of descending thoracic aortic pathology including emergent settings.

Last year in our institution, three patients with an average age of 46,6 years (range 39-55) underwent emergent TEVAR for acute aortic injury during traffic accident; two in the car, and one on the motorcycle. The technical success rate was $100 \%$. A standard Medtronic thoracic aortic stent graft VALIANT was used. There was no procedure-related complications: no stroke, spinal cord ischemia, or complications connected with vascular access. In all three cases graft was positioned bellow left subclavian artery. All three patients had polytrauma, and after successful graft implantation underwent other surgical procedures (ruptured diaphragm, subdural hematoma, multiple pelvic fractures).

Fortunately all three patients overcome their complicated medical conditions. The control MSCT of aorta, before hos- pital discharge, has shown widely patent stent grafts with no migration and no change in the configuration.

After 1 year, 8 month and 6 month of follow up, our patients confirm that TEVAR is a reliable method for the treatment of traumatic thoracic aortic injuries, even favorable in comparison with historical open surgery, with good results in the short- and medium-term follow-up.

KEYWORDS: thoracic aorta, endovascular repair, thoracic stent graft, traumatic aortic injury.

\section{Received: $5^{\text {th }}$ Mar 2013}

*Address for correspondence: Klinički bolnički centar Zagreb, Kišpatićeva 12, HR10000 Zagreb, Croatia.

Phone: +385-1-2388-888

E-mail: maja.strozzi@gmail.com

\section{Literature}

1. Xenos ES, Abedi NN, Davenport DL, Minion DJ, Hamdallah O, Sorial EE, et al. Meta-analysis of endovascular vs. open repair for traumatic descending thoracic aortic rupture. J Vasc Surg. 2008;48(5):1343-51.

2. Cambria RP, Crawford RS, Cho JS, Bavaria J, Farber M, Lee WA, et al; GORE TAG investigators: A multicenter clinical trial of endovascular stent graft repair of acute catastrophes of the descending thoracic aorta. J Vasc Surg. 2009;50(6):1255-64.

3. Fernandez V, Mestres G, Maeso J, Dominguez JM, Aloy MC, Matas M. Endovascular treatment of traumatic thoracic aortic injuries: short- and medium-term Follow-up. Ann Vasc Surg, 2010;24(2):160-6.

4. Mitchel ME, Rushton FW Jr, Boland AB, Byrd TC, Baldwin ZK. Emergency procedures on the descending thoracic aorta in the endovascular era. J Vasc Surg. 2011;54(5):1298302. 